\title{
Studies of Vapour Permeation of Chlorinated Hydrocarbons Through Natural Rubber-Clay Nanocomposite Membranes
}

\author{
Sharika Nair ${ }^{1,2}$, Jogitha $\mathrm{PG}^{1}$, Sreelakshmi Rajeevan ${ }^{1}$, Soney C George ${ }^{1,2,{ }^{*}}$ \\ ${ }^{1}$ Centre for Nanoscience \& Technology, Dept of Basic Sciences, Amal Jyothi Engineering College, \\ Kanjirapally, Kerala, India \\ ${ }^{2}$ International and Interuniversity Centre for Nanoscience \& Nanotechnology, Mahatma Gandhi University, \\ Kottayam, P.D Hills P.O India
}

\begin{abstract}
Natural Rubber/ clay nanocomposite membranes were prepared by blending on a two-roll mill followed by compression moulding in a hydraulic press. Vapour permeation studies were conducted with various chlorinated hydrocarbons for the characterization of membrane. Special attention has been given to the effect of clay concentration, type of clay, size of penetrant and type of vulcanization on the vapour transport behaviour of composites. It was found that permeability is low at higher clay concentration and also the permeability coefficient decreases with increase in penetrant size. Peroxide vulcanized membrane exhibit lowest vapour permeability than conventionally and efficiently vulcanized membrane, which can be attributed to the higher crosslink density of peroxide vulcanized membranes. The effect of clay concentration on the sorption and diffusion behaviour of composites is also investigated.
\end{abstract}

Keywords: Natural rubber, Clay, Vapour permeation.

\section{INTRODUCTION}

Vapour permeation is an efficient membrane-based process has now emerged as new industrial technology and is considered as an alternative to pervaporation process. Compared to pervaporation, the effective membrane area requirement is lower for vapour permeation process [1]. Also, the feed is a vapour and not a liquid, so there is no phase change or significant temperature difference across the membrane. The permeation of vapours through an organic membrane, such as a polymer film, is a complex process that consists of four processes: the sorption of vapour molecules on the surface of the membrane; the dissolution of the vapours inside the membrane; the diffusion through it; and, finally, the desorption of vapours from the other surface of the membrane [2]. The establishment of a chemical potential gradient due to the difference in the partial pressures of permeate across the membrane is the driving force for the mass transfer of permeate from the feed side to the permeateside of the membrane [3]. The investigation on permeability and selectivity of a membrane is important to determine the structure-property relationship in polymer nanocomposites and is found to be a good technique for characterizing the composites [4]. Hence it helps to determine the fundamental functions for practical applications of the composite

"Address correspondence to this author at the Centre for Nanoscience \& Technology, Dept of Basic Sciences, Amal Jyothi Engineering College, Kanjirapally, Kerala, India; Tel: 9447870 319;

E-mail: soneygeo@gmail.com membrane. Permeability determine the usage of polymer as a barrier material for various applications. Besides these advantages, a study of solvent vapour permeation offers direct practical conclusions for the understanding and rational design of volatile organic components (VOC) vapour recovery from contaminated air streams, opportunities for energy saving, solvent reuse, and can also be used for separation of azeotropic mixture [5]. In order to obtain a good permeation rate and a high degree of separation for a feed mixture, it is essential to choose the right membrane as well as the optimum operating conditions [6].

Polymer-clay nanocomposites are hybrid composite materials in which the clay particles are dispersed in polymer matrix [7]. Nanoclays, such as montmorillonite, hectorite, bentonite etc. provide nanoscale dispersion of the inorganic phase within the polymer matrix and have been widely used as an inorganic reinforcement for polymer matrices [6]. For true nanocomposites, the clay nanolayers must be uniformly dispersed (exfoliated) in the polymer matrix, as opposed to being aggregated as tactoids or simply intercalated [8]. When nanolayers have been exfoliated, the improvement in properties can be seen as an increase in tensile properties, as well as enhanced barrier properties, decreased solvent permeability, and increased thermal stability and flame retardance [9]. Nanoscale structure effects and the interaction between inorganic and organic materials are responsible for these enhanced properties in polymer matrix [10]. A multitude of packaging and adhesive applications have rendered 
barrier property improvements of polymer nanocomposites a promising and viable technology [11].

In most theoretical treatises the nanocomposite is considered to consist of a permeable phase (polymer matrix) in which non-permeable nanoplatelets is dispersed. The main factors that influence the permeability of a nanocomposite are; the volume fraction of the nanoplatelets; their orientation relative to the diffusion direction; their aspect ratio, nature of the polymer, clay content, size and shape of penetrant, nature of crosslinks, and degree of dispersion of silicate layers [12]. In polymer-nanocomposite membranes the presence of the inorganic phase can influence the size and the number of the free volume holes. Consequently, the change in the permeability of such systems is a balance between the barrier properties of the impermeable nanoplatelets and the possible increase of the free volume of the matrix [13]. The decrease in vapour permeation through polymer nanocomposites was attributed to extremely high aspect ratio of clay platelets, so that the permeant molecules have to wiggle around them, which increased the tortuosity of the path of vapour or solvent molecules as molecules diffused into the nanocomposite [14].

There exist interesting reports on the vapor permeation through different polymer membranes [15]. For example, a decrease in the diffusivity with an increase in the size of penetrant has been reported by many investigators. Very recently, much attention has beenpaid on rubber-clay nanocomposites, dueto their wide application in making useful material like hoses, belts, cover strips, O-lings, and gaskets in making automotive. In addition, natural rubber nanocomposites with good vapour permeation properties are required in applications like tires, bladder, and packaging materials etc [16]. Reduction of gas permeability shown by rubber nanocomposites suggesting their application as inner liners. Studies of gas transport in rubber/clay nanocomposites are fairly recent. Kojima et al. [17] synthesized nitrile rubber/clay hybrid with $70 \%$ of the permeability of acrylonitrile-butadiene rubber (NBR), while Gatos and Kocsis [18] investigated the transport properties of hydrogenated acrylonitrile-butadiene rubber (HNBR)/layered silicate nanocomposites. Other authors also reported vapour transport studies on NBR, [19] different types of butyl elastomers, [20] ethylene vinyl acetate (EVA), [21] styrene-butadiene rubber (SBR), [22] etc.
Studies showed that the presence of silicate nanolayers in a protonated form of butadiene and acrylonitrile copolymer reduces the composite permeabilities to hydrogen and water vapour about one-third in relation to pristine nitrile rubber. Alongside this, a great improvement in properties by exfoliation of silicate layers into 1,4-polyisoprene (synthetic) natural rubber (NR) and epoxidized natural rubber (ENR) [23] and ethylene propylene diene monomer (EPDM) have been reported. Kawasumi et al. reported that the permeability of hydrogen and water decreased to $70 \%$ by adding $3.9 \mathrm{vol} \%$ of montmorillonite into NBR [24]. NR/amine modified montmorillonite based vulcanizates prepared by two roll mixing were reported to have half the permeability of gum NR by Li et al. [25] Most of the work on natural rubber, however, has been limited to development of barrier properties of latex based products.

In this study natural rubber/clay nanocomposite membrane were prepared. Vapour permeation characteristics of these composite membrane using various chlorinated hydrocarbon vapours were analyzed. The influence of various vulcanizing systems, concentration of clay, type of clay and penetrant size on the vapour permeation behaviour was investigated.

\section{MATERIALS AND METHODS}

The natural rubber (ISNR-5) was supplied by Rubber Research Institute of India, Kottayam, Kerala. Nanoclays (closite 10A, 15A, 20A, 25 A, 30A, 93A) used as fillers were procured from Southern clay products U.S.A. The properties of nanoclays are available elsewhere [26].

Elemental sulphur and dicumyl peroxide (DCP) were used as vulcanizing agents in this study. The other ingredients used were $\mathrm{N}$-cyclohexyl-2-benzo thiazyl sulphenamide (CBS), Zinc oxide ( $\mathrm{ZnO})$, Stearic acid and Tri methyl dihydroquinoline (TDQ). The solvents $\mathrm{CH}_{2} \mathrm{Cl}_{2}, \mathrm{CHCl}_{3}$, \& $\mathrm{CCl}_{4}$ (Merck India Ltd, Mumbai) were used without further purification. All other rubber ingredients were of laboratory reagent grade, supplied by Bayer India Ltd. Mumbai India.

\section{Preparation of NR/Clay Nanocomposite Membrane}

Compounding of NR and clay was done on a tworoll mixing mill (friction ration 1:1:4); according to ASTM D 15-627. The basic formulation used is given in Table 1. 
Table 1: Formulation of Mixes (in phr*)

\begin{tabular}{|c|c|c|c|c|c|c|c|c|c|c|c|c|c|c|c|c|}
\hline Ingredient & A & B & C & D & E & $\mathbf{F}$ & G & H & I & $\mathbf{J}$ & $\mathbf{K}$ & $\mathbf{L}$ & M & $\mathbf{N}$ & 0 & $\mathbf{P}$ \\
\hline NR & 100 & 100 & 100 & 100 & 100 & 100 & 100 & 100 & 100 & 100 & 100 & 100 & 100 & 100 & 100 & 100 \\
\hline Clay & - & - & - & $10^{1}$ & $10^{1}$ & $10^{1}$ & $1^{2}$ & $2^{2}$ & $3^{2}$ & $5^{2}$ & $10^{2}$ & $15^{2}$ & $10^{3}$ & $10^{4}$ & $10^{5}$ & $10^{6}$ \\
\hline Stearic Acid & 2.0 & 2.0 & - & 2.0 & 2.0 & - & 2.0 & 2.0 & 2.0 & 2.0 & 2.0 & 2.0 & 2.0 & 2.0 & 2.0 & 2.0 \\
\hline $\mathrm{ZnO}$ & 5.0 & 5.0 & - & 5.0 & 5.0 & - & 5.0 & 5.0 & 5.0 & 5.0 & 5.0 & 5.0 & 5.0 & 5.0 & 5.0 & 5.0 \\
\hline CBS & 1.0 & 2.0 & - & 1.0 & 2.0 & - & 1.0 & 1.0 & 1.0 & 1.0 & 1.0 & 1.0 & 1.0 & 1.0 & 1.0 & 1.0 \\
\hline TDQ & 1.0 & 1.0 & - & 1.0 & 1.0 & - & 1.0 & 1.0 & 1.0 & 1.0 & 1.0 & 1.0 & 1.0 & 1.0 & 1.0 & 1.0 \\
\hline Sulphur & 2.0 & 0.50 & - & 2.0 & 0.5 & - & 2.0 & 2.0 & 2.0 & 2.0 & 2.0 & 2.0 & 2.0 & 2.0 & 2.0 & 2.0 \\
\hline DCP & - & - & 4.0 & - & - & 4.0 & - & - & - & - & - & - & - & - & - & - \\
\hline
\end{tabular}

.-parts per hundred rubber; 1-Cloisite 10A; 2-Cloisite 20A; 3-Cloisite 93A; 4-Cloisite 15A; 5-Cloisite 25A; 6-Cloisite 30B.

The vulcanization ingredients were added to the elastomer before the incorporation of the filler and finally, the sulphur was incorporated. Uncured rubber compounds were analysed by Monsantorheometer R100. All compounded composites were then compression moulded using the electrically heated platens of hydraulic press at $150^{\circ} \mathrm{C}$ and under a pressure of $6.7 \mathrm{MPa}$ for optimum cure. The samples were cured for the optimum cure time $t_{90}$, which represents the time to attain $90 \%$ of the maximum rheometric torque. Further details can be seen elsewhere.The average thickness of the membrane was found to be $200 \mu \mathrm{m}$.

In order to study the effect of vulcanizing systems on the role of nanoclays, NR was differently vulcanized with conventional (CV), efficient (EV) and peroxide (DCP) systems (D, E \& F respectively) along with nanoclay (cloisite 10A-10 phr) and it was compared with corresponding pure vulcanizing systems $(A, B, C$ respectively). In order to study the effect of concentration of modified nanoclays, NR was conventionally vulcanized along with cloisite $20 \mathrm{~A}$ with a concentration of $1 \mathrm{phr}, 2 \mathrm{phr}, 3 \mathrm{phr}, 5 \mathrm{phr}, 10 \mathrm{phr}$ and $15 \mathrm{phr}$ and is denoted as $\mathrm{G}, \mathrm{H}, \mathrm{I}, \mathrm{J}, \mathrm{K}$ and $\mathrm{L}$ respectively. Different types of organoclays such as cloisite 10A, 20A, 93A, 15A, 25A, and 30B were used to prepare NR-Clay composites and they were represented as $D, K, M, N, O$ and $P$. All these samples were conventionally vulcanized.

\section{Vapour Permeation Studies}

For vapour permeation studies, NR-clay nanocomposite membrane with nano clay were dipped in a suitable solvent for 2 hours for a pre-treatment. The thicknesses of the unswollen samples were measured at several points using a screw gauge. The vapor permeability was determined at $27^{\circ} \mathrm{C}$ by measuring the weight loss of small vials filled with solvents and tightly closed by the sorbed pre-treated membrane. The weight loss is proportional to time, area of the membranes and pressure inside the vials and is inversely proportional to the thickness of the membrane. The permeabilityis calculated using the following equation,

Permeability $\mathrm{P}=\Theta \mathrm{h} / \mathrm{ApM}$

where $\Theta$ is the slope of the vapour permeation graph (i.e., the quantity of solvent sorbed vs. time), $\mathrm{h}$ is the thickness of the membrane, $\mathrm{A}$ is the area of the film used, $p$ is the pressure difference across the membrane and $\mathrm{M}$ is the molecular weight of the permeant used. The unit of the permeability is $\mathrm{cm}^{2} / \mathrm{s}$.

\section{Sorption Studies}

A circular sample of the dry membrane was vacuum dried at room temperature for $24 \mathrm{~h}$. It was immersed in chlorohydrocarbons taken in diffusion bottles and kept in a thermostatically controlled oven. After attaining equilibrium, it was again taken out and the solvent adhered to the sample was removed by means of a tissue paper and quickly weighed on an electronic balance with an accuracy of $0.0001 \mathrm{~g}$. Since the weighing's were done within 30s, the error associated with the evaporation of solvents is negligible. The experiments were duplicated or triplicated in most cases. The sorption coefficient can be calculated from the following equation [11]

$\mathrm{S}=\mathrm{M} \infty / \mathrm{M}_{0}$

where $\mathrm{M} \infty$ is the mass of the solvent sorbed at equilibrium and $\mathrm{M}_{0}$ is the initial mass of the polymer sample. 
The degree of crosslinking was determined by the following relation [27];

$\gamma=1 / 2 \mathrm{Mc}$

where $\mathrm{Mc}$ is the molecular weight between cross-links.

Mc can be calculated with Flory-Rehner relation [28]:

$\mathrm{Mc}=-\rho_{\mathrm{pVs}} \Phi^{1 / 3} /\left[\ln (1-\Phi)+\Phi+\chi \Phi^{2}\right]$

where $\rho_{\mathrm{p}}$ is the density of the polymer, Vs is the molar volume of the solvent, $\Phi$ is the volume fraction of the swollen rubber, and $\chi$ is the interaction parameter.

\section{RESULTS AND DISCUSSION}

\section{Vapour Permeation Studies}

\section{Effect of Vulcanizing Systems}

Vulcanization leads to the formation of finely and uniformly distributed crosslinks in the rubber chain and prevents the polymer chains from moving independently, leads to a stable morphology. The flexibility of crosslinks has a significant role in deciding the permeation behavior. Generally, as the flexibility of crosslinks increases permeant diffusivity increases, leading to an increase in permeability. The structure of crosslinks formed during the vulcanization process is given in Figure 1. As shown in the figure, the peroxide vulcanized membrane contains stable and rigid $\mathrm{c}-\mathrm{c}$ bonds. In the conventionally vulcanized membrane, highly flexible polysulphides linkages are formed. In EV membranes, stable and rigid mono and disulfide crosslinks are formed. The flexibility of crosslinks in various systems is in the order $C V>E V>D C P$. Generally, the conventionally vulcanized sample permeates more due to the flexible poly sulfidic crosslinks and the peroxide vulcanized sample the least because of its rigid C-C bonds. Thus, based on the flexibility of bonds, the permeability could be in the order $\mathrm{CV}>\mathrm{EV}>\mathrm{DCP}$. But the experimentally determined permeability coefficients for different vulcanizing systems are given in Figure 2.
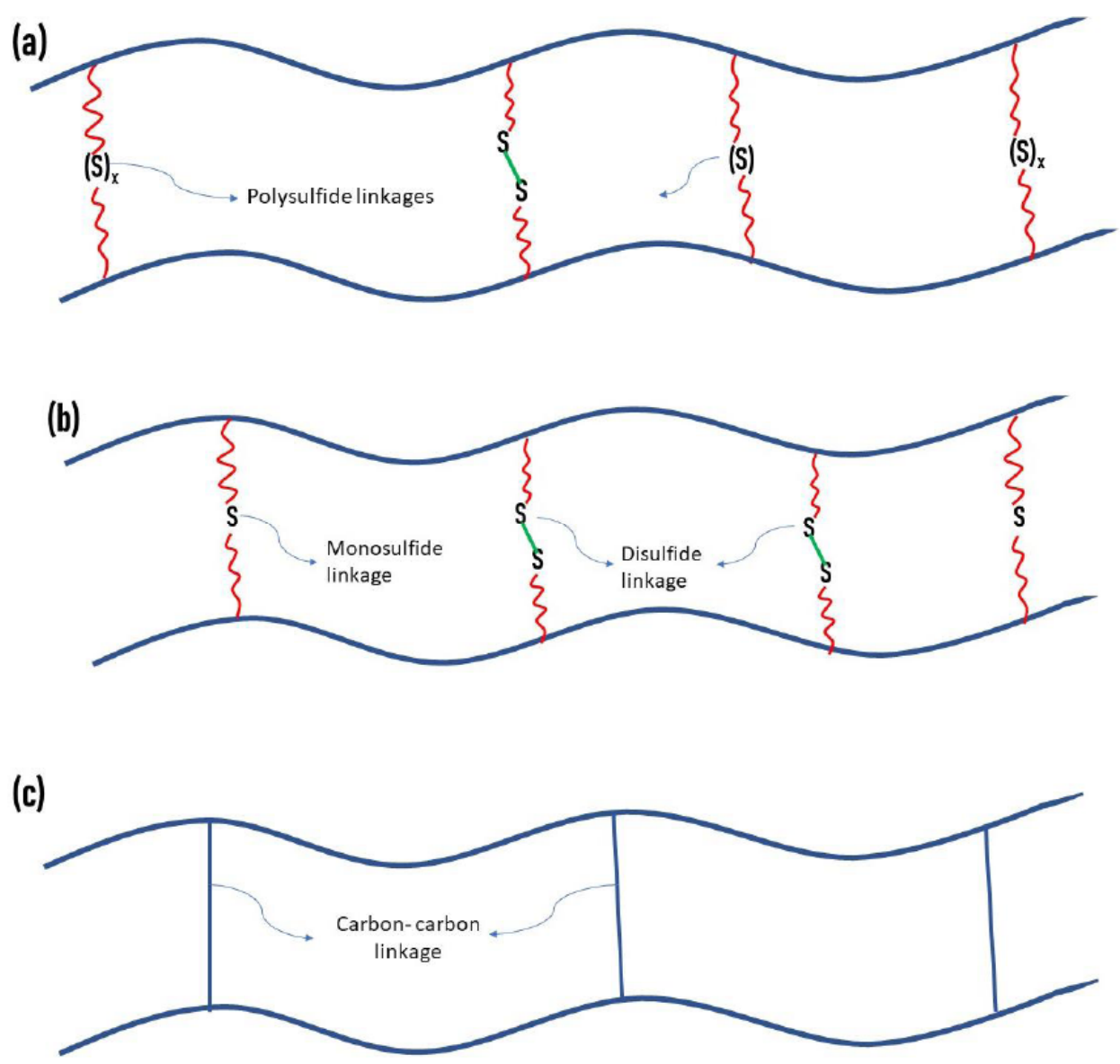

Figure 1: The structure of crosslinks formed during vulcanisation process (a) CV, (b) EV and (c) DCP. 


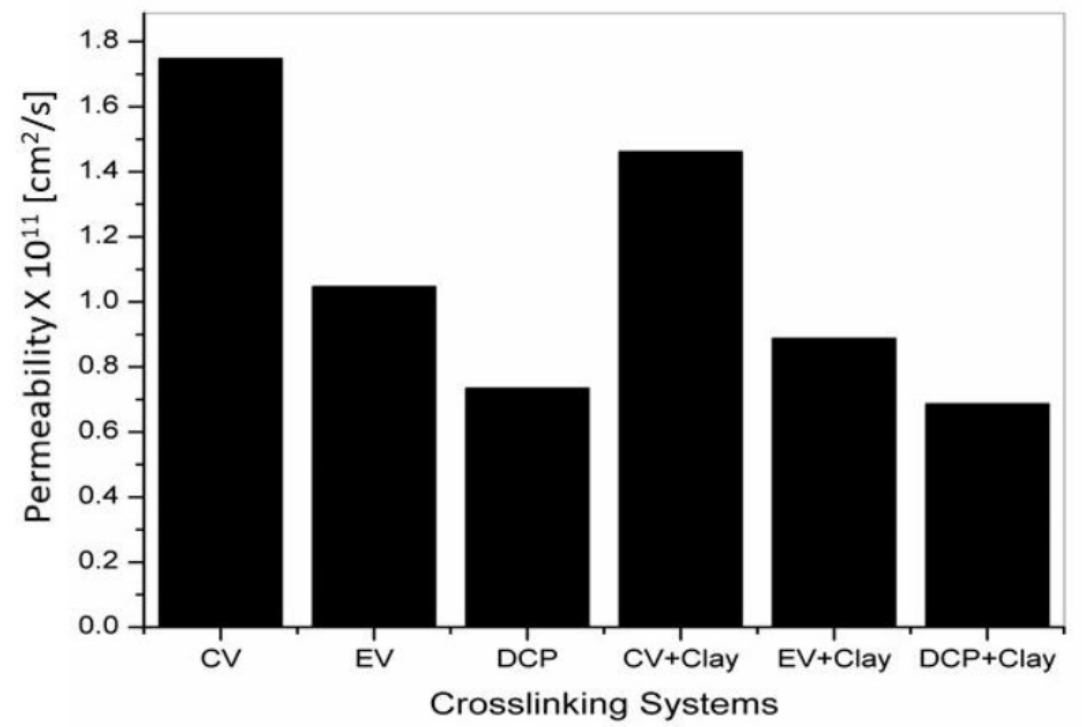

Figure 2: The effect of vulcanizing systems on the vapour permeability of NR membrane with and without clay.

Irrespective of the solvents used, the permeability coefficients are highest for conventionally vulcanized sample and lowest for peroxide vulcanized sample, efficiently vulcanized sample take intermediate position. By the addition of nanoclay, there occurs a decrease in the permeability coefficient, which is also in the order $\mathrm{CV}+\mathrm{Clay}>\mathrm{EV}+\mathrm{Clay}>\mathrm{DCP}+$ Clay. This behaviour can also be explained on the basis of degree of crosslinking of the vulcanized samples which is given in Table 2.

Table 2: $\quad \gamma$ Values for Vulcanized NR Membrane with and Without Clays

\begin{tabular}{|c|c|c|}
\hline Sample & Mc & $\gamma(\mathbf{m o l} / \mathbf{c c})$ \\
\hline \hline A & 37.275 & 1.341 \\
\hline B & 27.438 & 1.822 \\
\hline C & 14.561 & 3.434 \\
\hline D & 36.671 & 1.364 \\
\hline E & 26.089 & 1.916 \\
\hline F & 9.620 & 5.197 \\
\hline
\end{tabular}

It is very clear from the table that the highest crosslink density possessed by the DCP membrane with or without clay (C\&F) exhibit the lowest vapour permeability, and the lowest crosslink density possessed by CVmembrane (A\&D) exhibit the highest vapour permeability. As the number of crosslinks per unit volume of the polymer membrane increases, it becomes very difficult for the vapour molecules to pass through the tightly crosslinked system. Therefore, crosslink density and the nature of crosslinks influence the vapour permeation behaviour in these systems.

The degree of crosslinking in various systems increases in the order $\mathrm{A}<\mathrm{D}<\mathrm{B}<\mathrm{E}<\mathrm{C}<\mathrm{F}$.

As the crosslinking density increases, the permeability also decreases and it follows in the order $A>D>B>E>C>F$. Thus, DCP vulcanized NR membrane with or without clay possess lowest vapour permeability.

\section{Type of Concentration of Clay}

The effect of concentration of nanoclay (Cloisite$20 \mathrm{~A}$ ) on the vapour permeability of NR/clay nanocomposite membranes $(\mathrm{G}, \mathrm{H}, \mathrm{I}, \mathrm{J}, \mathrm{K}, \mathrm{L})$ are shown in Figure 3.

With the increase in the concentration of clay, the permeability sharply increases and reaches a maximum at $3 \mathrm{phr}$ (I) of clay and then decreases with an increase in the amount of filler. The two main factors that influence the permeability of the films are the availability of free volume in the polymer matrix and the flexibility of the membrane (crosslinking density). The transport behavior of NR/clay composites can be explained from the crosslink density values shown in Figure 4. It is clear from Figure 4 that sample I have low crosslinking density value and it possesses highly flexible polymer chains. Hence the vapour molecules can easily pass through the membrane. The degree of crosslinking in the various system is in the order $\mathrm{K} \mathrm{H}<$ 


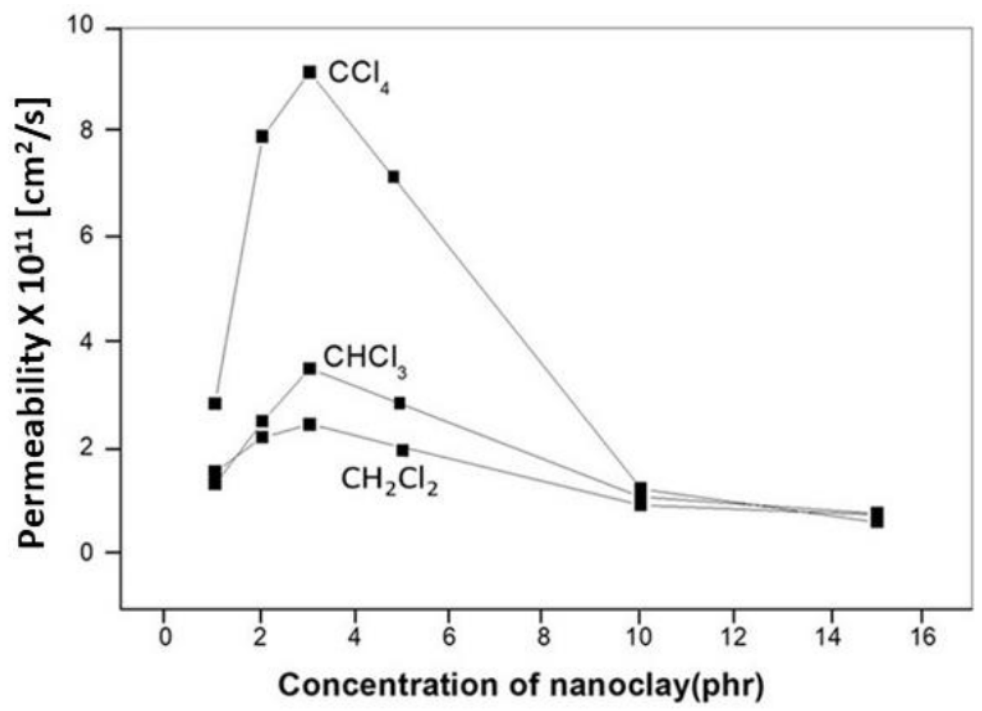

Figure 3: Effect of concentration of nano clay on the vapour permeability of NR/clay nanocomposites.

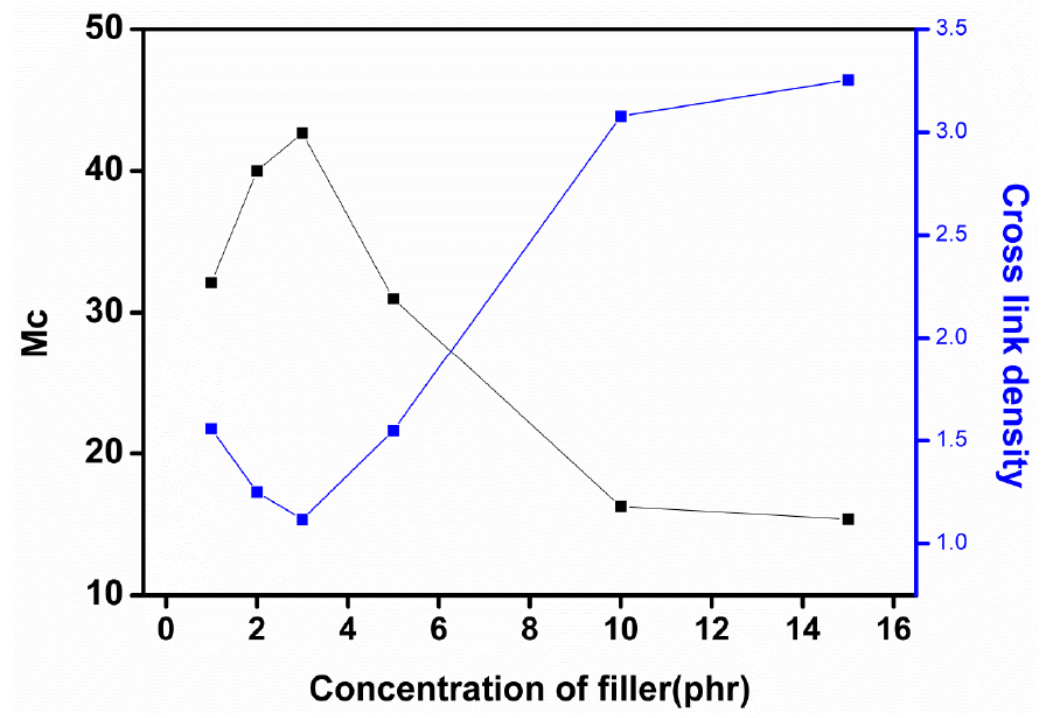

Figure 4: Effect of nanoclay concentration on the crosslinking density values of NR/clay composites.

$\mathrm{G}<\mathrm{J}<\mathrm{K}<\mathrm{L}$. Sample $\mathrm{L}$ possesses a maximum $\mathrm{Y}$ value and has low vapour permeation.

Even at very low filler loadings, these NR nanocomposite membranes exhibit a decrease in vapour permeation due to the increased tortuosity, reduced polymer mobility and available free volume.

The low vapour permeability of $\mathrm{J}, \mathrm{K}, \mathrm{L}$ can also be explained by XRD analysis of these composites. XRD results of NR/clay nanocomposites can be seen elsewhere [26]. It shows that in $\mathrm{J}, \mathrm{K}, \mathrm{L}$ the clay was well intercalated in the rubber matrix as it evident from the increase in the interlayer distance $(2.60,2.52$, $2.55 \mathrm{~nm}$ respectively compared to $2.19 \mathrm{~nm}$ of $\mathrm{D}$ ) and decrease of angle $2 \theta\left(3.39,3.50,3.45^{\circ}\right.$ respectively compared to $4.02^{0}$ of $\mathrm{D}$ ). These intercalated clay particles decrease the free volume in composites, it become difficult for the vapour molecules to pass through this system and decrease the vapour transport.

\section{Type of Modified Clay}

The vapour permeability of NR-clay composites with different types of clay are shown in Figure 5. The permeability was very much reduced in sample $\mathrm{K}$ (Cloisite-20A), and also the vapour permeability of $\mathrm{N}$, Pare comparable to that of $\mathrm{K}$. D has the maximum permeability. 


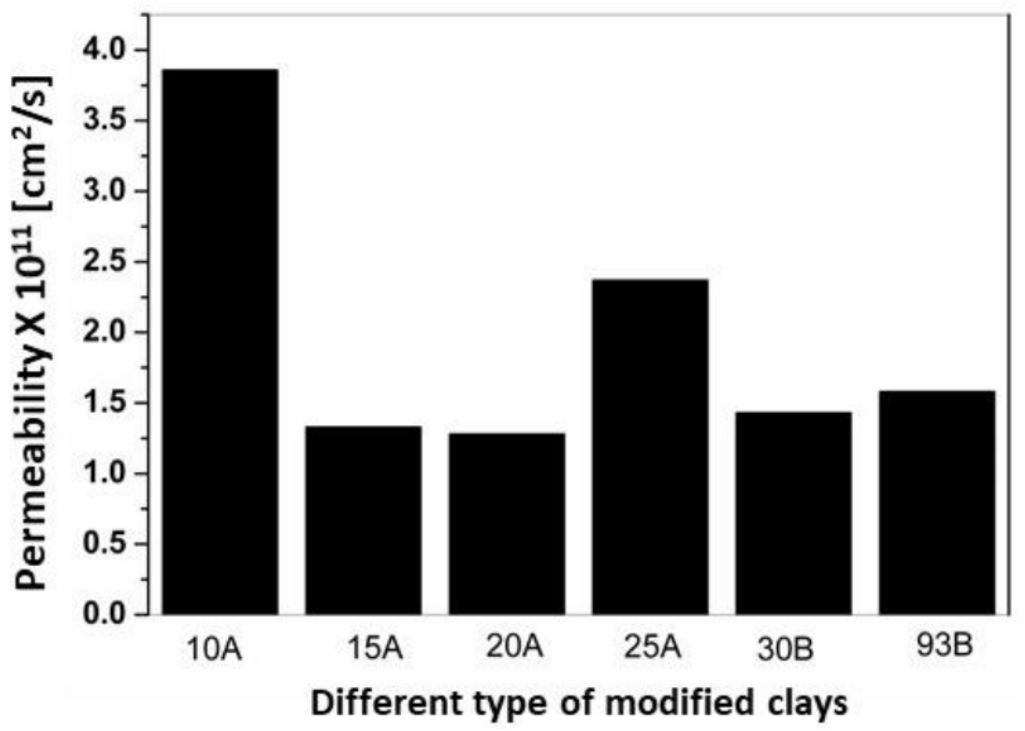

Figure 5: Effect different type of modified clay on vapour permeability of NR/Clay composites.

This observed transport behavior can be explained from the degree of crosslinking in these samples. Crosslinking density values are shown in Figure $\mathbf{6}$. The lowest permeation behavior of Sample $\mathrm{K}$ is due to its highest crosslinking density value. Sample D shows high vapour permeation since it possesses low crosslinking density. XRD results also reveal that the intercalation of NR occurs very well in sample K, N,P as it evident from the increase in the interlayer distance $(2.52,1.98,2.97 \mathrm{~nm})$ and decrease of angle $2 \theta(3.50$, $\left.1.93,2.97^{\circ}\right)$ compared to that of $D\left(2.19 \mathrm{~nm}\right.$ and $\left.4.02^{\circ}\right)$ [26]. Hence highly crosslinked polymer chains and wellintercalated clay particles reduce the available free volume very much in $\mathrm{K}$ and it possesses low permeation behavior.

\section{Effect of Penetrant Size}

The penetrants used in this study are $\mathrm{CH}_{2} \mathrm{Cl}_{2}$, $\mathrm{CHCl}_{3}$, and $\mathrm{CCl}_{4}$. The vapour permeability increases with increasing the penetrant size as shown in Figure 7. This order is found to be the same in all systems studied and is explained using polymer-solvent interaction parameters/solubility parameter values. The solubility parameter values of NR and solvents are given in Table 3.

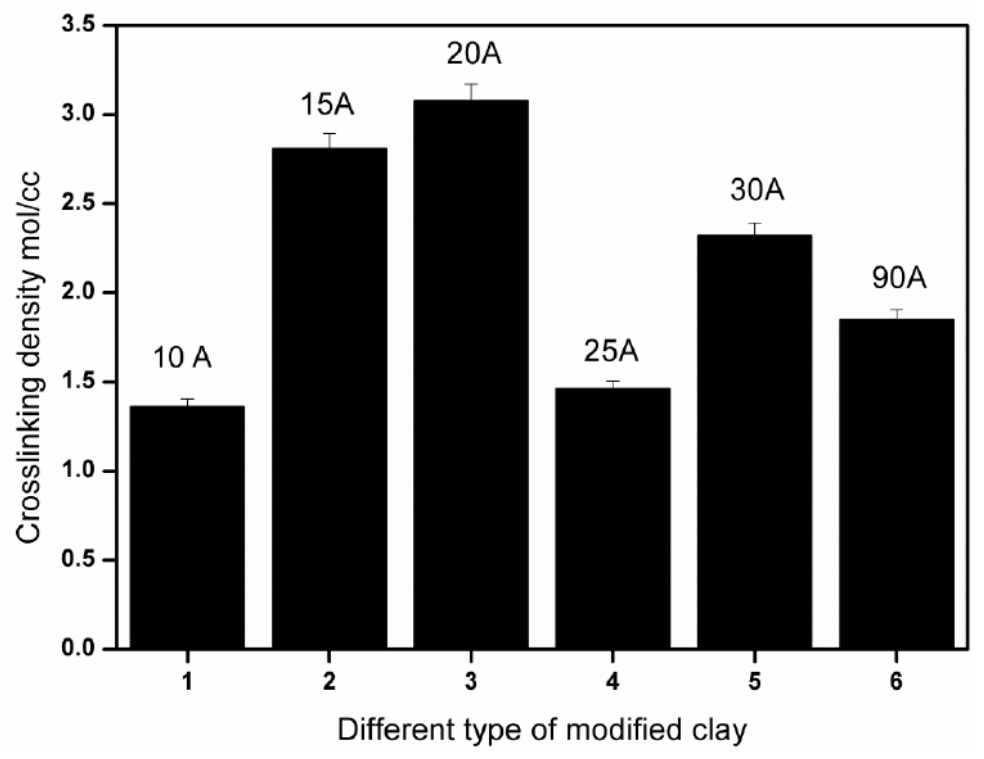

Figure 6: Effect of different types of modified clay on degree of cross linking of NR/clay composites. 


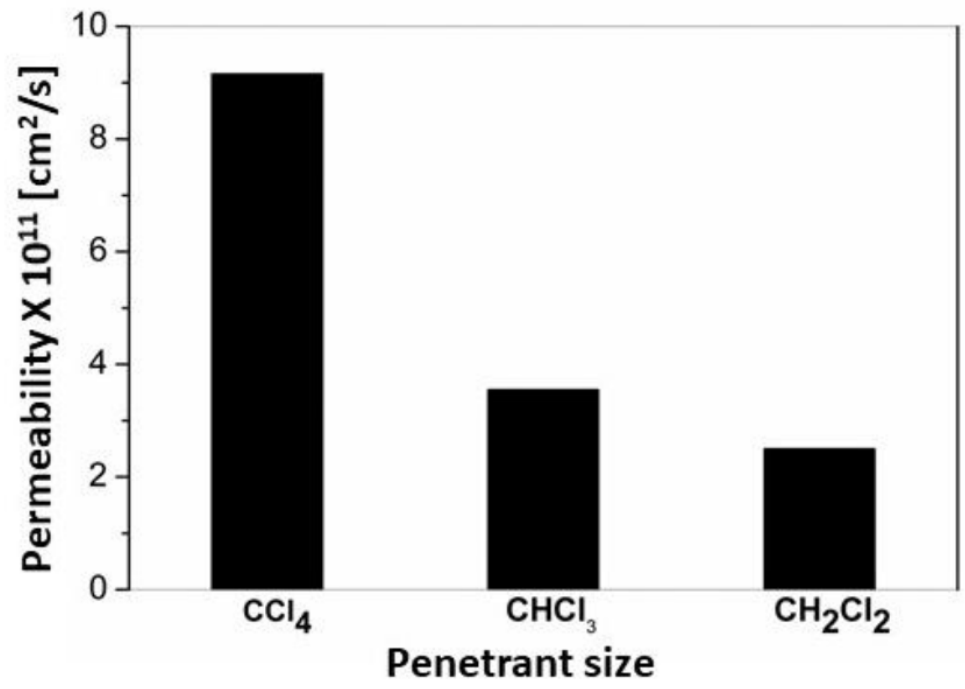

Figure 7: Effect of penetrant size on the vapour permeability of NR/Clay composite.

Polymer-solvent interaction parameter was determined using the equation [17]

$$
X=\beta+\frac{V_{S}}{R T}\left(\delta_{S}-\delta_{p}\right)^{2}
$$

where, $\delta_{\mathrm{S}}$ and $\delta_{\mathrm{P}}$ are the solubility parameters of the solvent and the polymer, $\beta$ the lattice constant, $R$ is the universal gas constant and $T$ is the absolute temperature. The polymer-solvent interaction parameter is a dimensionless parameter, which characterizes the interaction between polymer segments with the solvent. A low value of $(\delta s-\delta p)$ gives low interaction parameter and it indicates a stronger interaction with the solvents and the composite.

Table 3: Solubility Parameter Values of NR and Various Solvents

\begin{tabular}{|c|c|c|c|c|}
\hline System & $\mathbf{N R}$ & $\mathbf{C H}_{2} \mathrm{Cl}_{\mathbf{2}}$ & $\mathbf{C H C l}_{3}$ & $\mathbf{C C l}_{4}$ \\
\hline \hline Solubility parameter $(\delta)$ & 7.9 & 9.7 & 9.3 & 8.6 \\
\hline
\end{tabular}

Generally, as the ( $\delta \mathrm{s}-\delta \mathrm{p})$ values decreases, the interaction between the composite and the solvent increases. The ( $\delta s-\delta p)$ value is less for natural rubber$\mathrm{CCl}_{4}$ and it is increases in the order NR- $\mathrm{CCl}_{4}<\mathrm{NR}$ $\mathrm{CHCl}_{3}<\mathrm{NR}-\mathrm{CH}_{2} \mathrm{Cl}_{2}$. Hence the highest $\mathrm{CCl}_{4}$ permeability value is due to its strong interaction with NR.

\section{Sorption and Diffusion Studies of NR/Clay Composite Membrane}

With an increase in the concentration of clay, diffusivity as well as sorptivity of NR/clay composites sharply increases and reaches a maximum at $3 p h r(I)$ of clay and then decreases. These are shown in Figure 8 and Figure 9. This observed behavior can be explained on the basis of the degree of crosslinking in composites given in Figure 4. It is clear from the figure that $\mathrm{g}$ value is minimum for the sample I and maximum for the sample L. Hence, I possess a high permeability coefficient and $\mathrm{L}$ have low permeability coefficient value. The highest diffusion coefficient showed by sample I can also be explained on the basis of degree of crosslinking present in composites.

\section{CONCLUSIONS}

Transport of chlorinated hydrocarbon vapours through NR-clay nanocomposite membranes showed that the permeation process was influenced by vulcanizing systems, the concentration of clay, type of clay, and penetrant size.

Effect of vulcanizing systems on the permeation coefficient is increased in the order $C V>E V>D C P$. This behavior is explained on the basis of the degree of crosslinking of the vulcanized samples. It was also observed that permeation coefficient values increased with clay concentration up to $3 p h r$ and then decreased. At higher clay concentration permeation coefficient value decreased due to the high degree of crosslinking and also the presence of intercalated clay particles reduces the vapour transport. Investigation of permeability data in NR/clay composites showed that the permeation coefficient values were greatly affected by a different type of modified clay. The effect of the structure of penetrant on permeation properties was 


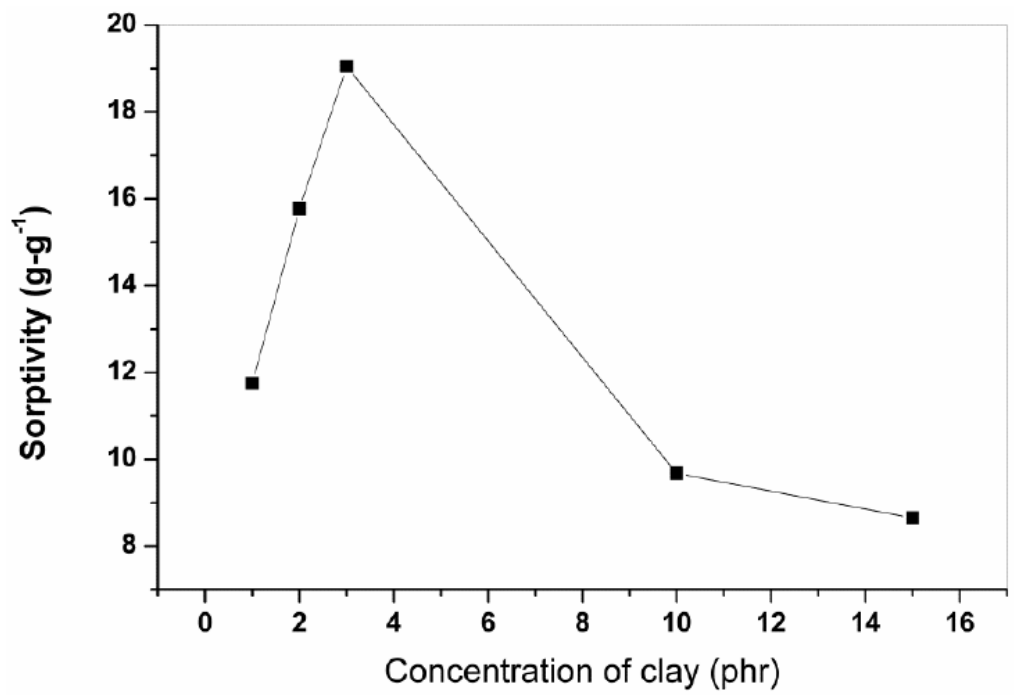

Figure 8: Effect of concentration of clay on the sorption coefficient of NR/clay composites.

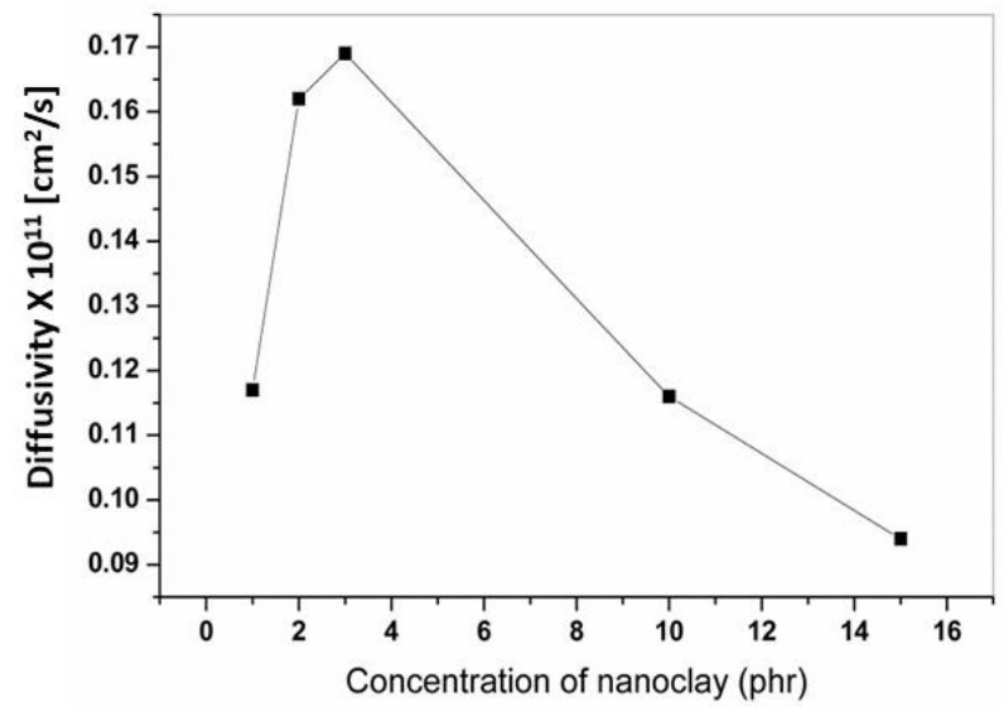

Figure 9: Effect of clay concentration on the Diffusion coefficient of NR/Clay composites.

examined and it was found that the permeability coefficient increased when the difference in solubility parameter between polymer and solvent is low.

\section{REFERENCES}

[1] Kumari P, Radhakrishnan CK, Unnikrishnan G, Varghese S, Sujith A. Natural rubber/acrylonitrile butadiene rubber blend membranes: vapor permeation properties. Chemical Engineering \& Technology: Industrial Chemistry-Plant Equipment-Process Engineering-Biotechnology 2010 Jan; 33(1): 97-102. https://doi.org/10.1002/ceat.200900268

Choudalakis G, Gotsis AD. Permeability of polymer/clay nanocomposites: a review. European polymer journal 2009 Apr 1; 45(4): 967-84. https://doi.org/10.1016/j.eurpolymj.2009.01.027

[3] Bolto B, Hoang M, Xie Z. A review of water recovery by vapour permeation through membranes. Water research.
2012 Feb 1; 46(2): 259-66. https://doi.org/10.1016/j.watres.2011.10.052

[4] Sunilkumar M, Sujith A, Unnikrishnan G. CP Mohamed Kutty, M Jahfar. Organic vapor permeation through membranes based on ethylene propylene diene monomer and polyvinyl chloride. Journal of elastomers and plastics 2011; 1-14.

[5] Kutty CM, Jahfar M, Sunilkumar M, Sujith A, Unnikrishnan G. Organic vapor permeation through membranes based on ethylene propylene diene monomer and polyvinyl chloride. Journal of Elastomers \& Plastics 2012 Sep; 44(5): 405-18. https://doi.org/10.1177/0095244311429737

[6] Maria HJ, Lyczko N, Nzihou A, Joseph K, Mathew C Thomas S. Stress relaxation behavior of organically modified montmorillonite filled natural rubber/nitrile rubber nanocomposites. Applied clay science. 2014 Jan 1; 87: 1208. https://doi.org/10.1016/j.clay.2013.10.019

[7] Anilkumar S, Kumaran MG, Thomas S. Characterization of EVA/clay nanocomposite membranes and its pervaporation performance. The Journal of Physical Chemistry B 2008, 
13,4009-15.

https://doi.org/10.1021/jp7096444

[8] LeBaron PC, Wang Z, Pinnavaia TJ. Polymer-layered silicate nanocomposites: an overview. Applied clay science 1999 Sep 1; 15(1-2): 11-29.

https://doi.org/10.1016/S0169-1317(99)00017-4

[9] Maji PK, Das NK, Bhowmick AK. Preparation and properties of polyurethane nanocomposites of novel architecture as advanced barrier materials. Polymer 2010 Mar 2; 51(5): 1100-10.

https://doi.org/10.1016/j.polymer.2009.12.040

[10] Lopez-Manchado MA, Herrero B, Arroyo MJ. Preparation and characterization of organoclay nanocomposites based on natural rubber. Polymer International. 2003 Jul; 52(7): 1070-7. https://doi.org/10.1002/pi.1161

[11] Zeman S, Kubík L. Permeability of polymeric packaging materials. Technical Sciences/University of Warmia and Mazury in Olsztyn 2007(10): 26-34. https://doi.org/10.2478/v10022-007-0004-6

[12] Kim JK, Hu C, Woo RS, Sham ML. Moisture barrier characteristics of organoclay-epoxy nanocomposites. Composites Science and Technology 2005 Apr 1; 65(5): 80513.

https://doi.org/10.1016/j.compscitech.2004.10.014

[13] Bedane $\mathrm{AH}$, Huang $\mathrm{Q}$, Xiao $\mathrm{H}$. Mass transfer of water vapor, carbon dioxide and oxygen on modified cellulose fiber-based materials. Nordic Pulp \& Paper Research Journal 2012 May $1 ; 27(2): 409-17$ https://doi.org/10.3183/nppri-2012-27-02-p409-417

[14] Gusev AA, Lusti HR. Rational design of nanocomposites for barrier applications. Advanced Materials. $2001 \mathrm{Nov}$; 13(21): 1641-3.

https://doi.org/10.1002/1521-4095(200111)13:21<1641::AIDADMA1641>3.0.CO;2-P

[15] Takahashi S, Goldberg HA, Feeney CA, Karim DP, Farrell M, O'leary K, Paul DR. Gas barrier properties of butyl rubber/vermiculite nanocomposite coatings. Polymer 2006 Apr 19; 47(9): 3083-93. https://doi.org/10.1016/j.polymer.2006.02.077

[16] Wang $\mathrm{Y}$, Zhang $\mathrm{H}, \mathrm{Wu} \mathrm{Y}$, Yang J, Zhang L. Structure and properties of strain-induced crystallization rubber-clay nanocomposites by co-coagulating the rubber latex and clay aqueous suspension. Journal of applied polymer science. 2005 Apr 15; 96(2): 318-23.

https://doi.org/10.1002/app.21408

[17] Kojima Y, Fukumori K, Usuki A, Okada A, Kurauchi T. Gas permeabilities in rubber-clay hybrid. Journal of Materials Science Letters 1993; 12(12): 889-90. https://doi.org/10.1007/BF00455608

[18] Gatos KG, Karger-Kocsis J. Effect of the aspect ratio of silicate platelets on the mechanical and barrier properties of hydrogenated acrylonitrile butadiene rubber (HNBR)/layered silicate nanocomposites. European polymer journal 2007 Apr
1; 43(4): 1097-104.

https://doi.org/10.1016/j.eurpolymj.2007.01.032

[19] Hwang WG, Wei KH, Wu CM. Mechanical, thermal, and barrier properties of NBR/organosilicate nanocomposites. Polymer Engineering \& Science 2004 Nov; 44(11): 2117-24. https://doi.org/10.1002/pen.20217

[20] Maiti M, Bhowmick AK. Effect of polymer-clay interaction on solvent transport behavior of fluoroelastomer-clay nanocomposites and prediction of aspect ratio of nanoclay. Journal of applied polymer science 2007 Jul 15; 105(2): 43545.

https://doi.org/10.1002/app.26052

[21] Bhattacharya M, Biswas S, Bandyopadhyay S, Bhowmick AK. Influence of the nanofiller type and content on permeation characteristics of multifunctional NR nanocomposites and their modeling. Polymers for Advanced Technologies 2012 Mar; 23(3): 596-610. https://doi.org/10.1002/pat.1930

[22] Bhattacharya M, Biswas S, Bhowmick AK. Permeation characteristics and modeling of barrier properties of multifunctional rubber nanocomposites. Polymer 2011 Mar 23; 52(7): 1562-76.

https://doi.org/10.1016/j.polymer.2011.01.055

[23] Vu YT, Mark JE, Pham LH, Engelhardt M. Clay nanolayer reinforcement of cis-1, 4-polyisoprene and epoxidized natural rubber. Journal of Applied Polymer Science 2001 Nov 7; 82(6): 1391-403. https://doi.org/10.1002/app.1976

[24] Kawasumi M, Hasegawa N, Kato M, Usuki A, Okada A. Preparation and mechanical properties of polypropyleneclay hybrids. Macromolecules 1997 Oct 6; 30(20): 6333-8. https://doi.org/10.1021/ma961786h

[25] Li P, Wang L, Song G, Yin L, Qi F, Sun L. Characterization of high-performance exfoliated natural rubber/organoclay nanocomposites. Journal of applied polymer science 2008 Sep 15; 109(6): 3831-8. https://doi.org/10.1002/app.28480

[26] George SC, Rajan R, Aprem AS, Thomas S, Kim SS. The fabrication and properties of natural rubber-clay nanocomposites. Polymer Testing 2016 May 1; 51: 165-73. https://doi.org/10.1016/j.polymertesting.2016.03.010

[27] Guizard C, Boutevin B, Guida F, Ratsimihety A, Amblard P, Lasserre JC, Naiglin S. VOC vapour transport properties of new membranes based on cross-linked fluorinated elastomers. Separation and purification technology $2001 \mathrm{Mar}$ 1; 22: 23-30. https://doi.org/10.1016/S1383-5866(00)00149-0

[28] Favre E, Schaetzel P, Nguygen QT, Clement R, Neel J. Sorption, diffusion and vapor permeation of various penetrants through dense poly (dimethylsiloxane) membranes: a transport analysis. Journal of Membrane Science 1994 Jul 4; 92(2): 169-84. https://doi.org/10.1016/0376-7388(94)00060-3

http://dx.doi.org/10.15379/2410-1869.2020.07.01.02

(C) 2020 Nair et al.; Licensee Cosmos Scholars Publishing House.

This is an open access article licensed under the terms of the Creative Commons Attribution Non-Commercial License (http://creativecommons.org/licenses/by-nc/3.0/), which permits unrestricted, non-commercial use, distribution and reproduction in any medium, provided the work is properly cited. 